This item was submitted to Loughborough's Research Repository by the author.

Items in Figshare are protected by copyright, with all rights reserved, unless otherwise indicated.

\title{
Component grouping for cell formation using resource elements
}

PLEASE CITE THE PUBLISHED VERSION

http://dx.doi.org/10.1080/00207549608904931

PUBLISHER

(c) Taylor \& Francis

VERSION

AM (Accepted Manuscript)

LICENCE

CC BY-NC-ND 4.0

REPOSITORY RECORD

Gindy, N., T.M. Ratchev, and Keith Case. 2019. "Component Grouping for Cell Formation Using Resource Elements”. figshare. https://hdl.handle.net/2134/13842. 
This item was submitted to Loughborough's Institutional Repository (https://dspace.lboro.ac.uk/) by the author and is made available under the following Creative Commons Licence conditions.

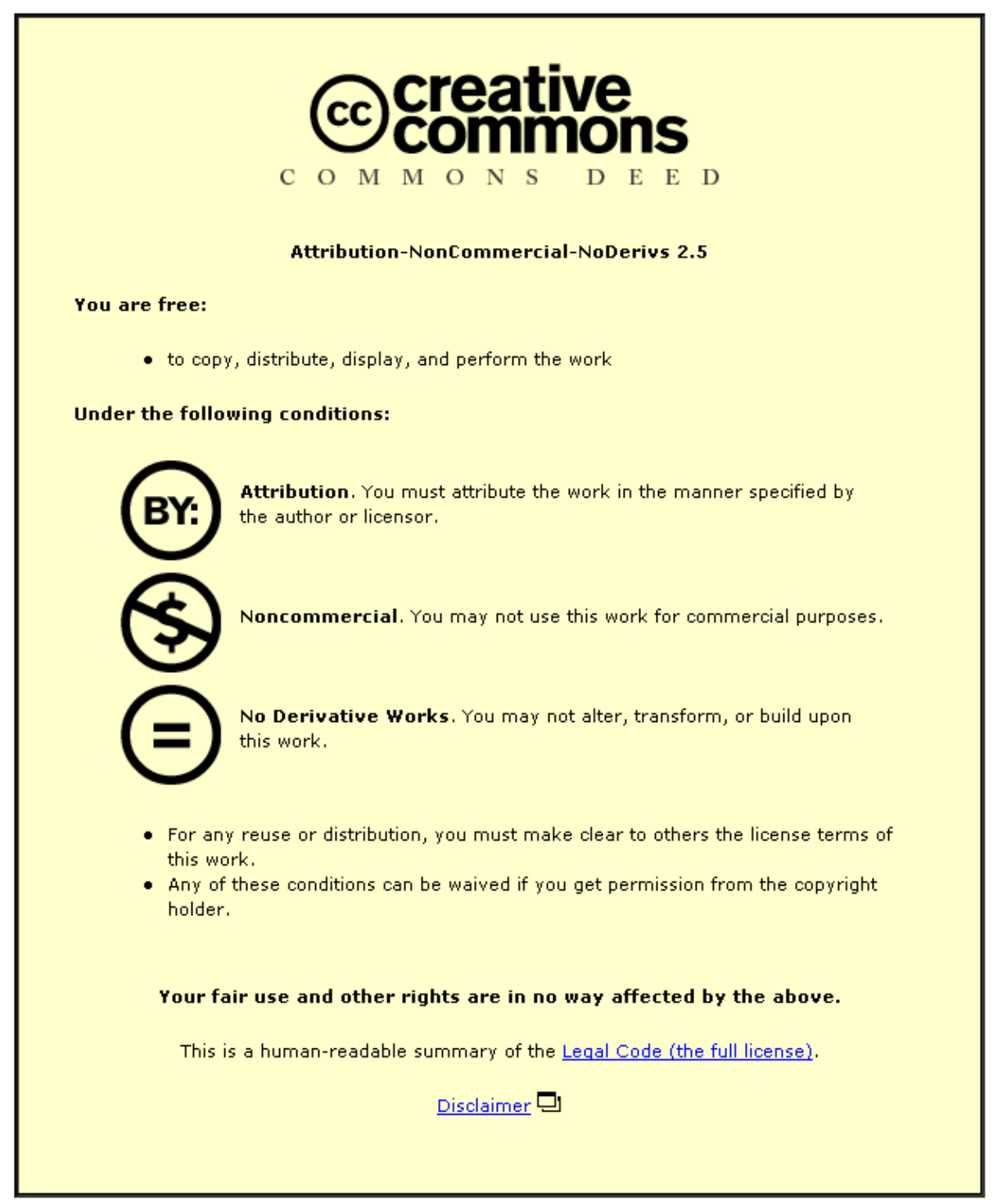

For the full text of this licence, please go to: http://creativecommons.org/licenses/by-nc-nd/2.5/ 


\title{
Component grouping for cell formation using resource elements
}

\author{
N. N. Z. GINDY†*, T. M. RATCHEV† and K. CASE $\ddagger$
}

\begin{abstract}
The work reported in this paper recognises that the traditional close association between components and a fixed route utilising a set of machine tools can no longer be relied upon as an appropriate basis for deciding component similarity and partitioning components into families in modern manufacturing applications. A new methodology for describing the capabilities of machine tools and machining facilities using generic capability units termed 'resource elements' is reported. REs are used to capture the processing requirements of components, assessing their similarity and a fuzzy grouping procedure is used for simultaneously grouping components and machine tools for cellular manufacturing applications. The reported results show that the use of resource elements leads to component groups that are more compact with better matching between processing requirements of components and the capabilities of the machine tools selected for their processing compared with the conventional machine-based approach.
\end{abstract}

\section{Introduction}

One of the areas of modern manufacturing in which component grouping plays an important role is cellular manufacturing. Here, significant efficiencies can be achieved by grouping machines and other supporting equipment into a cell dedicated to processing a sub-set of the total product mix manufactured in a plant (Wemmerlov and Hyer 1989). The total cellular manufacturing design problem including product-to-cell assignment, equipment selection, cell layout, control system design and staffing levels is complex and state-of-the-art solution techniques require substantial human intervention (Warren and Moodie 1993).

Cell formation is understood as the problem of identifying a set of component types that are suitable for manufacture on a group of machines (Singh 1993). A prime consideration in cell formation is to achieve 'appropriate' matching between the processing requirements of the partitioned part families and the capabilities of the machine tools in the corresponding cells. The requirements for achieving an optimum solution can, therefore, be stated as: (1) Maximising the number of components in the part family that require the full set machining resources allocated to a cell (maximum group compactness); (2) Minimising cell capability overlap, i.e. division of components into groups such that the need for repeated processing capabilities within a cell is minimised (Gindy et al. 1995). An adequate capture of component processing needs and the capabilities of machine tools that may be used for their processing and accurate assessment of the similarity between components are some of the critical factors influencing the success of component-to-cell allocation procedures. 
A variety of approaches have been used for defining component similarity, partitioning components into part families and the definition of the manufacturing cells to be used for their manufacture. These are normally referred to in the literature as 'part' and 'production methods' oriented approaches (Gupta 1993). In the 'part- oriented' approach, component functionality and its design features are considered the predominant attributes when deciding similarity between family members (Kusiak 1990). The lack of explicit manufacturing information is one of the major drawbacks of this approach when attempting to group components for manufacturing applications such as cellular manufacturing. In the 'production methods' oriented approach, component process planning information is first analysed and the machines used for part processing recorded and used as basis for clustering components into part families. This approach is found to be more effective in manufacturing applications and several theoretical platforms have been utilised to develop grouping algorithms based on this approach (Srinivasan and Narendran 1991).

There is an inherent inaccuracy in the component processing requirements when expressed by component routeings of machine tools-a representation which is used in the majority of the cell formation methodologies (Kang and Wemmerlov 1993). Two assumptions are common when defining component similarity based upon their processing routeings: (1) each component has a single (preferred) routeing of machine tools to be used for its manufacture; (2) components are considered similar as long as they visit the same machine tools.

The first assumption is fast becoming inappropriate; many modern manufacturing facilities contain a variety of alternative machine tools with similar and overlapping capabilities able to produce a wide variety of components using alternative processing methods. Moreover, the advances that have been made in developing generative process planning systems (Chang 1990, Gindy et al. 1993) capable of generating alternative processing routes for components and using multi-optimisation criteria to select from amongst alternatives, has made the predetermination of a single 'preferred' routeing increasingly inappropriate. The selection of the final component route may in many cases be determined by other factors such as scheduling and production planning constraints which determine machine availability.

The advent of modular, multi-axis machining centres and generic machine tools capable of processing an extremely wide variety of component geometries, have led to a dilution in the concept of similarity between the components if it is defined on the basis of commonality of the machine tools that the components visit. For example, generic machine tools, known as Hexapods (Variax 1994) are capable of machining components almost independently of their geometric shape. In such cases, claiming that the components that visit such machine tools are similar is almost meaningless, and the second assumption is certainly inappropriate.

The aim of the reported research is to provide an improved formalisation model for component processing requirements and machine tool capabilities to support the decision making processes relating to cell formation. The work recognises that the traditional close association between components and a fixed route utilising a set of machine tools can no longer be relied upon as an appropriate basis in deciding component similarity and partitioning components into families in modern manufacturing applications. A generic representation of the form-generating capabilities of the machine tools is used to provide a discriminating basis for capturing the processing requirements of the components and assessing their similarity. The approach is based on using 'resource elements' 
as generic capability primitives which capture the exclusive and shared capability boundaries between machine tools.

A fuzzy grouping methodology is used for concurrent component and machine tool clustering for cell formation. The methodology is based on the extended fuzzy C-means algorithm and cluster validation measure (Gindy et al. 1995). Component groups are created using resource elements which define their generic processing requirements. Machining cells are formed by selection of 'optimum' sets of machines matching the 'resource element' requirements of each component group.

The theoretical basis of the research is described in $\S 2$, the grouping methodology is outlined in $\S 3$ and case examples to demonstrate the approach are provided in $\S 4$.

\section{Basic definitions}

In this work, the processing requirements of components and the capabilities of machine tools are related to three basic levels. At the first level, 'form generating schemas' are used for representing the form generating capabilities of machining processes, used for component manufacture, at a level that is independent of the machine tools and machining facility used for process execution. The second level of abstraction is the machining 'operation' where machine specific attributes are attached to form generating schemas to relate them to the variety of machine tools that may be utilised for their execution. At the third level, 'resource elements' are used to relate both the form generating schema and operation levels to the processing system (machining facility/cell) in which they are used.

\subsection{Form generating schema and machining operations}

A form generating schema (FGS) is a technologically meaningful combination of a cutting tool of specific geometry, a set of relative motions between a part and the cutting tool, and the typical levels of technological output associated with using that combination of tool and relative motions. Form generating schemas therefore act as basic capability patterns that can be used for describing the individual/group of machining operation(s). An example of a form generating schema for face milling is shown in Fig. 1(a).

Machining operations (e.g. drilling. reaming, taper turning, etc.) describe how a form generating schema is executed on machine tool. They therefore inherit the attributes of the FGS they originated from and the division of motions between a part and the cutting tool from the machine tool used for their execution. A target machine tool performing an operation also provides the specific levels of technological output (e.g. surface finish, tolerances etc.) to be attached to the machining operation.

Based on the above definitions of FGSs and machining operations, a form generating schema can be considered as the root of several machining operations. It is a generalised representation of machining operations which use the same cutting tool type and legal sequence of relative motions between a part and cutting tool. Hence, machining operations are considered similar if they originate from the same form generating schema regardless of the actual machine tool used for their execution (see Fig. 1(b)).

\subsection{Resource elements}

The group of machine tools contained in a manufacturing facility/cell are described using a 
set of resource elements (RE). Each RE represents a collection of form generating schemas and is such that the exclusive and the shared capability boundaries between all the available

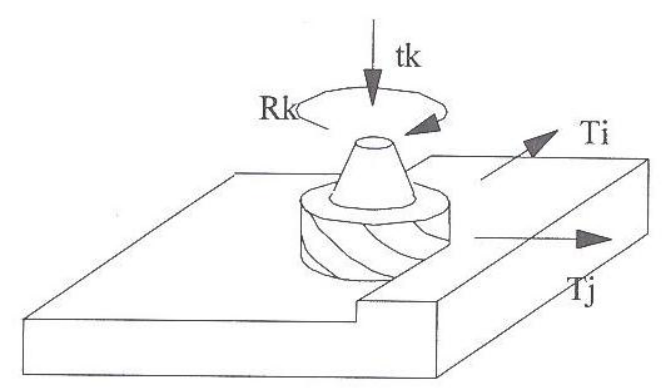

$\mathrm{R}, \mathrm{T}$ - formative motions (rotations and translations); $\mathrm{r}, \mathrm{t}$ - positioning motions (rotations and translations); $\mathrm{i}, \mathrm{j}, \mathrm{k}$ - motion axes.

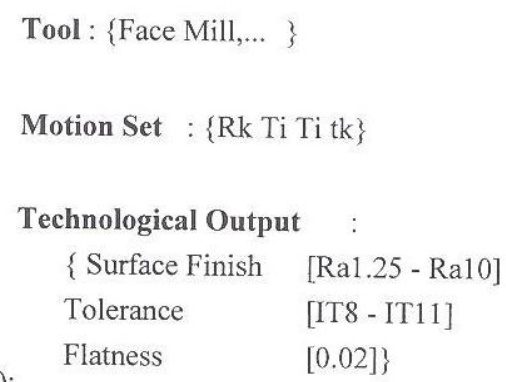

a) Form Generating Schema (Face Milling)

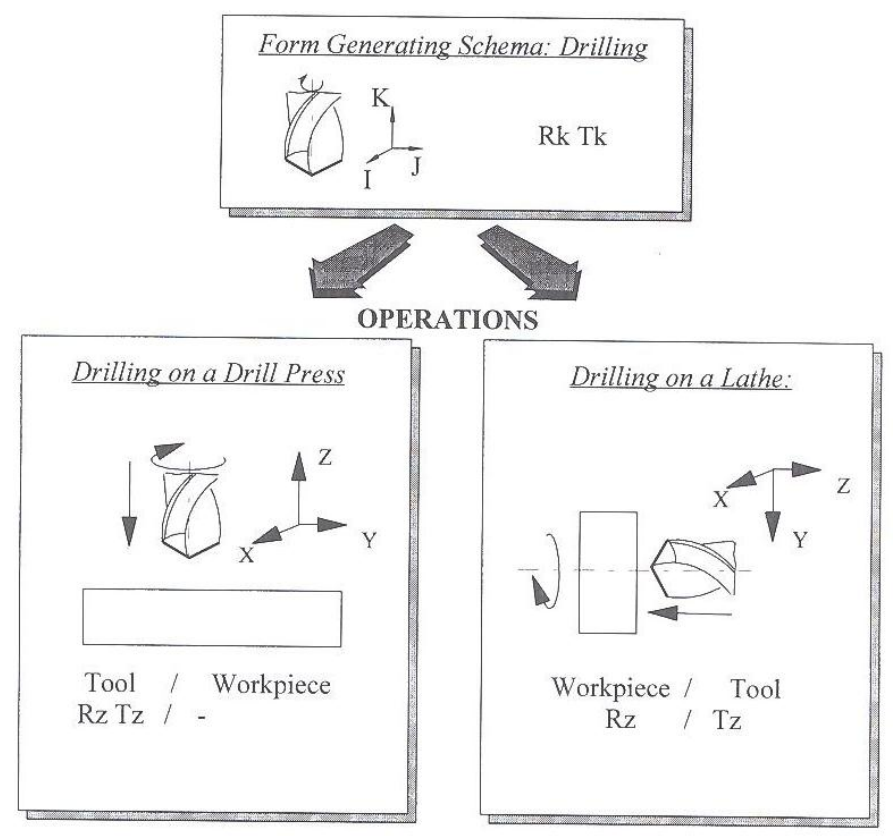

b) Machining Operations "Drilling"

Figure 1. Process capability models. (a) Form generating schemas (face milling).

(b) Machining operations 'drilling'.

machine tools contained in a manufacturing facility are uniquely identified (see Fig. 2). Resource element $R_{i}$ in $\Re$ is formally defined as: 
(1) $R_{i} \cap R_{j} \equiv 0, \forall R_{i}, R_{j} \in \mathfrak{l}$

(2) $f_{k} \in R_{i} \leftrightarrow f_{k} \notin R_{j}, \exists R_{i}, R_{j} \in \mathfrak{l}$

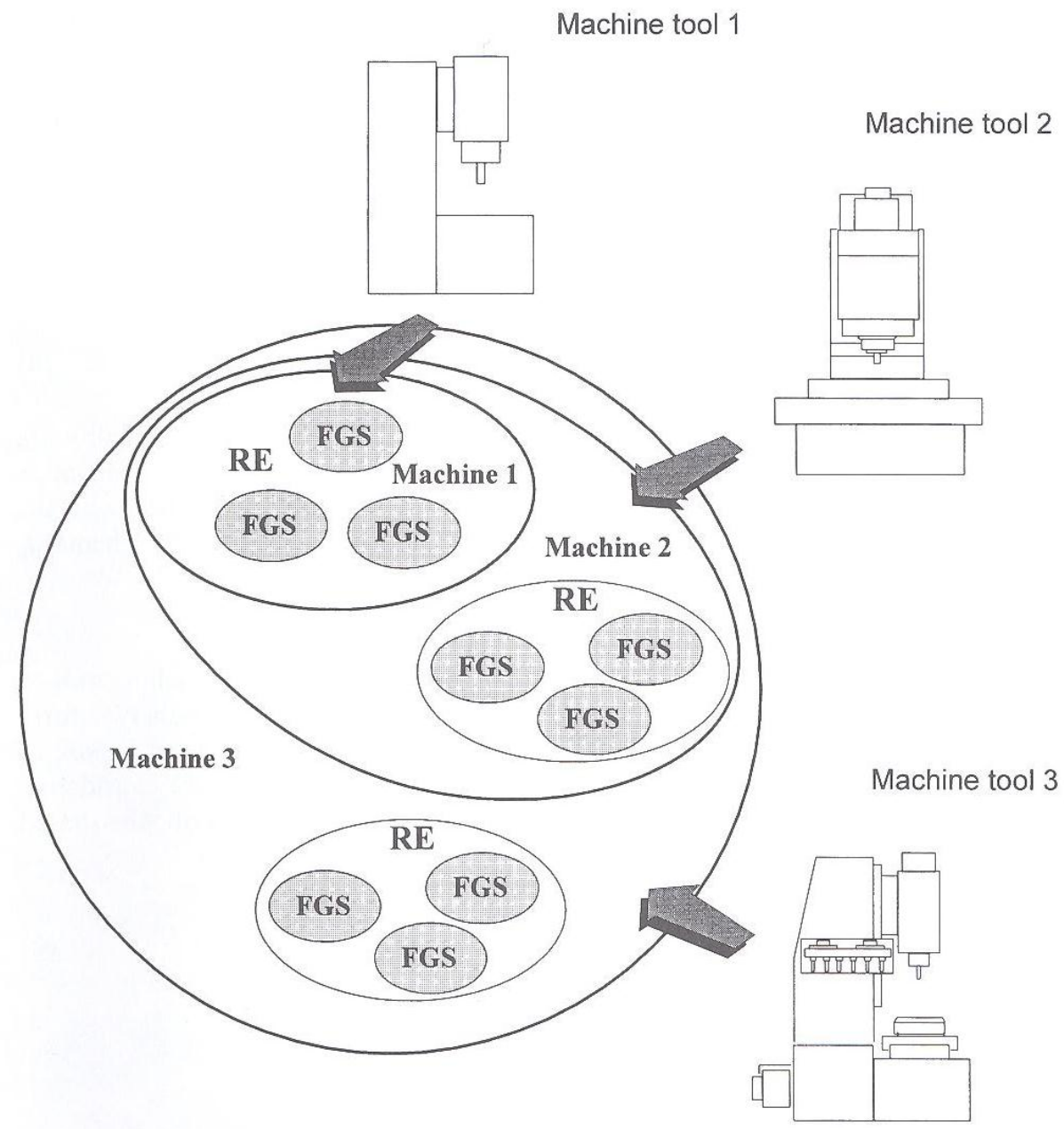

Figure 2. Diagrammatic representation of machining facility using REs.

where $\mathfrak{A}$ is the overall capability of the machining facility and $\mathrm{f}_{\mathrm{k}}$ is a FGS, which is part of the capability of the machining facility. Equation (1) represents two conditions: (1) REs are mutually exclusive (zero intersection between REs); (2) form generating schema can belong to only one RE.

Resource elements are machining facility-specific capability units which capture information relating to the distribution (commonality and uniqueness) of form generating schemas among the machine tools included in the machining facility definition. 


\subsection{Capability representation of the machining facilities}

The overall form generating capabilities contained in a machining facility can be defined as:

$$
F=f_{1}, f_{2}, \ldots, f_{n}
$$

where $f_{i}(\mathrm{i}=1,2, \ldots, n)$ are individual form generating schemas, and $F$ is the full set of FGS performed by the machining facility.

A machine tool is presented by the set of form generating schemas, as generalised patterns of the machining operations the machine can perform. The capability of an individual machine tool $M k$ in a machining facility $\mathbf{M}$ can, therefore, be represented by a vector:

$$
M_{k}=m_{1 k}, m_{2 k}, \ldots, m_{n k}, M_{k} \in \boldsymbol{M}
$$

where

$$
m_{i k}=\left\{\begin{array}{l}
1, \text { if FGS } f_{i} \text { belongs to machine } k, \\
0, \text { if FGS } f_{i} \text { does not belong to machine } k
\end{array}\right.
$$

The resource elements which describe the capability of a machining facility are defined using an iterative clustering procedure where each resource element is considered as a group of form generating schemas which appear together, with the same level of membership in each machine. For each two form generating schemas $f_{p}$ and $f_{q}$ in $\mathrm{F}$ :

$$
\text { IF } \forall M_{k} \in \mathrm{M}: m_{p k}=m_{q k} \text {, THEN cluster } f_{p} f_{q} \text { together }
$$

Form generating schemas either appear always together in each machine tool or neither of them is present. The procedure starts by clustering of each two form generating schemas in $\mathrm{F}$ (satisfying equation (5)) and gradually increasing the size of clusters until all possible combinations of form generating schemas are considered. The result is a definition of a finite set of resource elements which describe the shared and exclusive capabilities contained in the machining facility.

Each resource element $R_{j}$ is represented by the vector:

$$
R_{j}=r_{1 j}, r_{2 j}, \ldots, R_{n j}, R_{j} \in \mathfrak{l}
$$

where $r_{i j}$ is defined as:

$$
r_{i j}= \begin{cases}1, & \text { if } f_{i} \text { is a part of resource element } R_{j}, \\ 0, & \text { if } f_{i} \text { is not a part of resource element } R_{j}\end{cases}
$$

The uniqueness of the resource elements is described by:

$$
\sum_{k=1}^{N} r_{i k}=1, \forall i-1,2, \ldots n
$$

where $N$ is the overall number of resource elements in the machining facility.

Equation (7) guarantees that each form generating schema $f_{i}$ in $F$ belongs to only one RE and that there is no overlapping between the RE.

As an example, Fig. 3 shows the processing capabilities of a vertical machining centre in terms of its form generating capabilities and resource elements. The capability of the machining centre is defined first as a set of form generating schemas which are then grouped into three 
REs when the overall capability of the machining facility is considered. Although an RE can be attached to several machine tools in a cell, a form generating schema can belong only to one RE and a machine tool has to be capable of carrying out all the form generating schemas of the REs associated with it.

The steps involved in dividing a machining facility into a set of resource elements

\begin{tabular}{|l|l|l|l|}
\hline Cutting tool & Motion Set & F G S \\
\hline Rk Tk ti & Drilling \\
\hline Rk Tk & Roring \\
\hline
\end{tabular}

Processing capabilities of a vertical machining centre described as form generating schemas

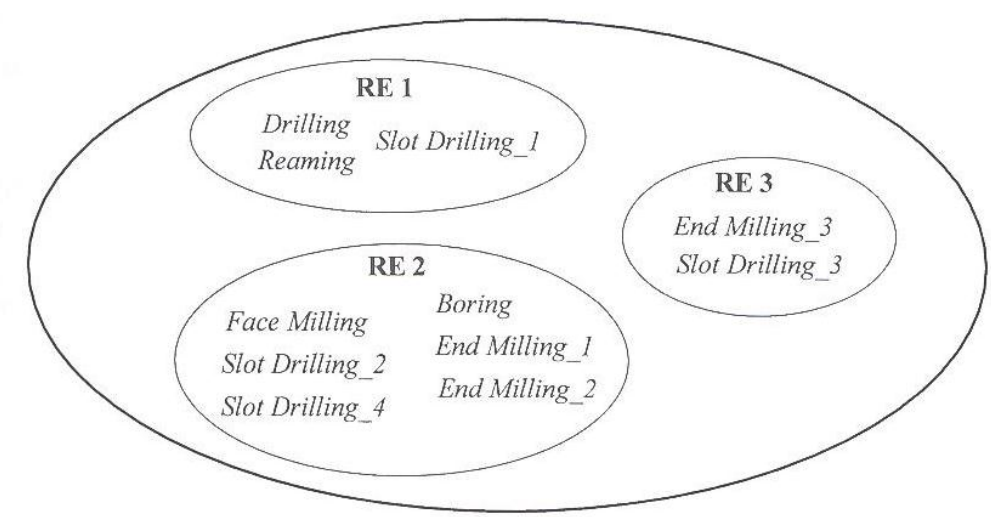

Processing capabilities described by resource elements

Figure 3. Capability break-up of vertical machining centre. 
can be summarised by the following algorithm:

Step 1. Define the full set of form generating schemas $F$.

Step 2. Define the capability of each machine tool using FGS.

Step 3. Select FGS $f_{r}$.

Step 4. Select $f_{i}(j \neq i)$.

Step 5. If $m_{i k}=m_{j k}$ for each machine $M_{k}(\mathrm{k}=1,2, \ldots, m)$ then cluster together $f_{i}$ and $f_{j}$

Step 6. Repeat steps 3, 4, 5 for all $i, j=1,2, \ldots, n$.

Step 7. Define each cluster of FGS as a RE.

Step 8. Using the clusters of FGS, represent each machine as a set of REs.

\section{4. $\quad$ Mapping of component set into RE space}

During process planning, the processing requirements of each component can be described by a set of resource elements needed for its completion. Components are represented as vectors and a component set is formally mapped into the RE Euclidean space $\boldsymbol{Q}$ such as:

$$
C_{j}=c_{i j}, c_{2 j}, \ldots, C_{N j}
$$

where $C_{j}$ is a component vector and the vector coordinates $C_{i j}(\mathrm{i}=1,2, \ldots, N)$ indicate the relationship between component $C_{j}$ and resource elements $R_{i}$ :

$$
C_{i j}=\left\{\begin{array}{l}
1, \text { if component } C_{j} \text { requires RE } R_{i}, \\
0, \text { if component } C_{j} \text { does not require RE } R_{i}
\end{array}\right.
$$

Partitioning of a set of components into part families is based upon optimising the division of components into a number of groups, where the set of resource elements used to represent each group describes the processing requirements of all the components belonging to the group.

\section{Cell formation methodology}

A diagrammatic representation of the overall strategy for the formation of machining cells utilising resource elements is shown in Fig. 4. A feature-based component data model is used to describe the component level data. Each component in the target set is represented by both its constituent form features and feature connectivity describing the relationships between adjacent component features (Gindy 1989, Gindy et al. 1993).

The first step in the cell determination process is a work content analysis phase which leads to the determination of the processing requirements of the target components. Work content analysis is based on attaching alternative feature technological solutions (TSFs) to each component feature. TSFs are generalised processing solutions for component features where each TSF is represented by the set of form generating schemas which are capable of producing the feature geometry and technological requirements (Gindy et al. 1993).

In order to provide a machine-independent but facility-specific description of the processing requirements of components, the machine tool data base, describing the available machine tools, is analysed and the capability of each machine represented as form generating schemas. The algorithm outlined in $\S 2.3$ is then applied to divide the capability of the machining facility into resource elements and each TSF represented by the resource elements needed for its completion. An algorithm based upon minimising the variety of resources needed for each component is used for optimising the resource set required for processing each component.

The output of the work content analysis phase is the total set of resource elements required 
for processing the target components.

\subsection{Cell formation}

The component-to-cell allocation methodology adopted in this work is based upon a modified fuzzy clustering approach with validity measure (Gindy et al. 1995).

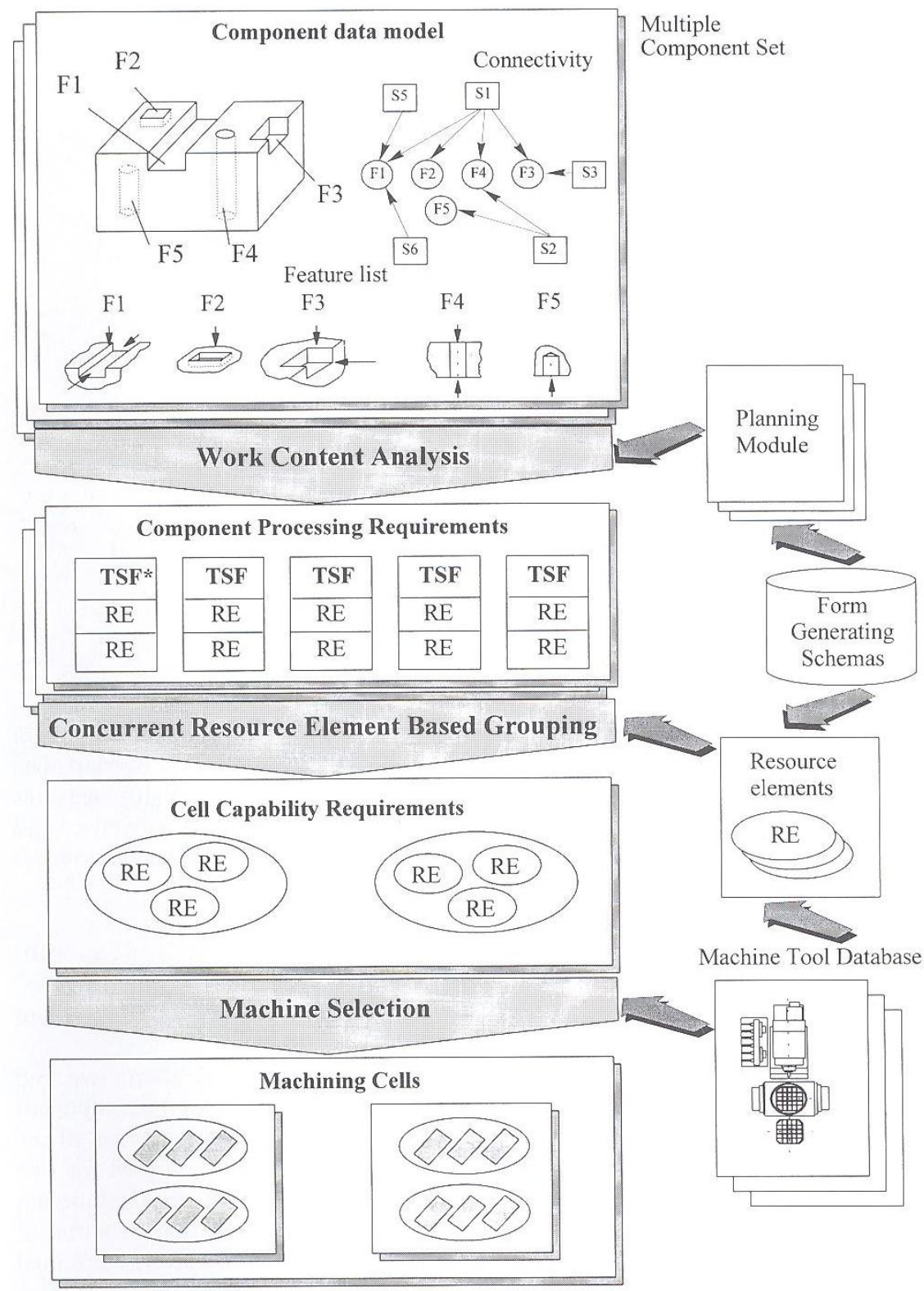

* TSF - Technological solution at a Feature Level 


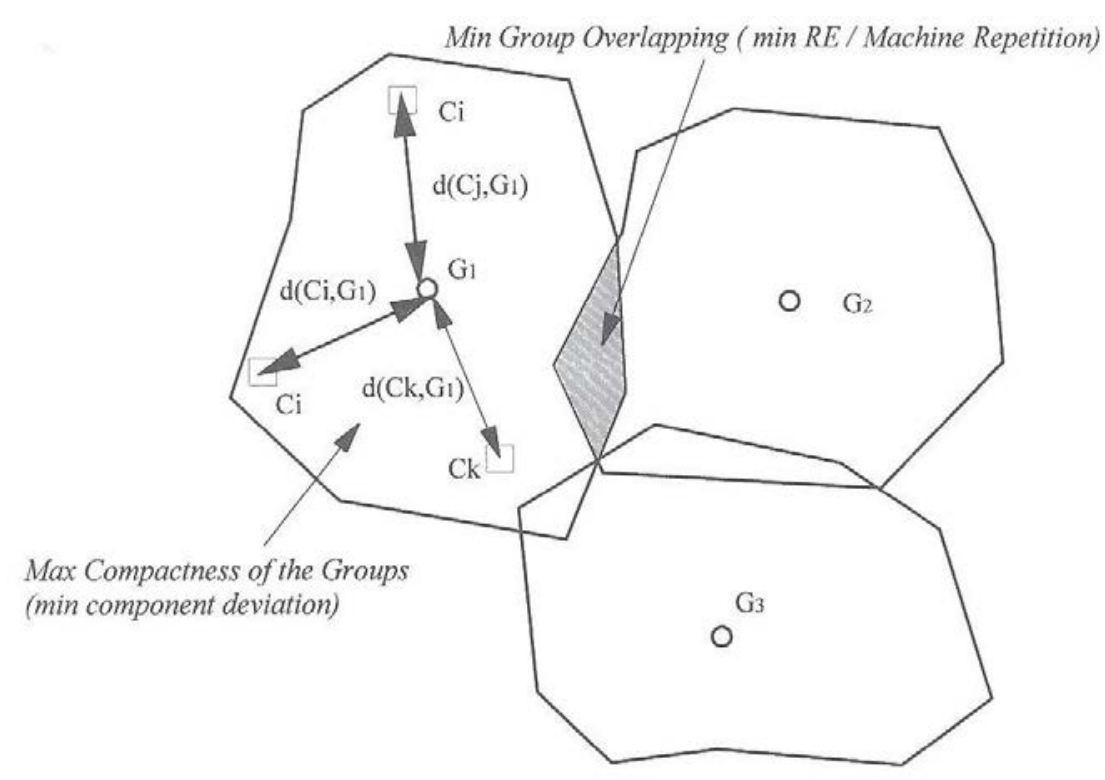

Figure 5. Validity measure for cell determination.

The grouping objective is to optimise the partition of the component set into a number of groups of maximum compactness and minimum capability overlap. The validation measure $R$ corresponding to this objective-see equation (10)-ensures that the similarity between the components belonging to each group is maximised and the capability overlap between the machine tools attached to the component groups is minimised (see Fig. 5).

$$
R=\frac{\lambda}{r} \rightarrow \min
$$

where $\lambda$, is the measure of group/cell compactness and $r$ represents the level of overlapping between the groups/cells.

Cell determination is based on divisive fuzzy algorithm which starts with two seed component groups and continues iteratively to modify the division of the component set into groups until a 'stop value' is reached beyond which further division of the component set is considered unprofitable. The validity measure is utilised for two purposes: (1) optimising the 
allocation (distribution) of components to the different groups ('stabilising the groups'), and (2) optimising group partition in terms of number of groups/machining cells. In the first case validity measure is calculated using REs (denoted as $\mathrm{R}^{\mathrm{r}}$ ), while in the second case the validity measure is machine- based (denoted as $\mathrm{R}^{\mathrm{m}}$ ) (see appendix A).

At each iterative step, components are clustered on basis of their processing requirements in terms of REs. The centroids of component groups describe the sets of resource elements required by the components in each group and component groups are considered stable and that 'optimum' partitioning has been achieved once the value of $\mathrm{R}^{\mathrm{r}}$ reaches a minimum.

\begin{tabular}{|c|c|c|}
\hline \multicolumn{2}{|r|}{ Machines } & \multirow[b]{2}{*}{ Resource Elements } \\
\hline Code & Name & \\
\hline 1 & Vertical Borer & B2 \\
\hline 2 & Turret Drill & D2, D3 \\
\hline 3 & Slotting Machine & D2, S2 \\
\hline 4 & Turning Lathe & $\mathrm{Tl}$ \\
\hline 5 & Shaper & S3 \\
\hline 6 & Turning Lathe & $\mathrm{Tl}, \mathrm{B} 2$ \\
\hline 7 & Horizontal Milling Machine & M2, D3, B2 \\
\hline 8 & Drill & D3 \\
\hline 9 & Turning Lathe & $\mathrm{Tl}, 82$ \\
\hline 10 & Turning Lathe & $\mathrm{Tl}$ \\
\hline II & Bridge Mill & M2, D3 \\
\hline 12 & Turning Lathe & $\mathrm{Tl}$ \\
\hline 13 & CNC Shaft Lathe & $\mathrm{Tl}$ \\
\hline 14 & GTinder & $\mathrm{S} 2$ \\
\hline 15 & Shaper & S3 \\
\hline 16 & Radial Drill & D2, D3 \\
\hline 17 & Drill & D2 \\
\hline 18 & Grinder & Gl \\
\hline 19 & Grinder & Gl \\
\hline 20 & Drill & $\mathrm{D} 2$ \\
\hline 21 & Grinder & $\mathrm{Gl}$ \\
\hline 22 & Turning Lathe & Tl, 82 \\
\hline 23 & Turning Lathe & $\mathrm{T} 2$ \\
\hline 24 & CNC Machining Centre & D2,D3 \\
\hline 25 & Drill & D2, D3 \\
\hline 26 & Milling Machine & M2 \\
\hline 27 & Turning Lathe & $\mathrm{Tl}$ \\
\hline 28 & Slotting Machine & $\mathrm{S} 2$ \\
\hline 29 & Turning Lathe & $\mathrm{Tl}$ \\
\hline 30 & Turning Lathe & $\mathrm{Tl}$ \\
\hline 31 & Turning Lathe & $\mathrm{Tl}, \mathrm{T} 2$ \\
\hline 32 & Grinder & Gl \\
\hline 33 & Radial Drill & D2, D3 \\
\hline 34 & Drill & D3 \\
\hline${ }_{-}^{1}$ & Turning Lathe & Tl, T2, Т3 \\
\hline$\overline{36}$ & Drill & D3, D2 \\
\hline 37 & Turning Lathe & $\mathrm{Tl}, \mathrm{T} 2$ \\
\hline 38 & Turning Lathe & $\mathrm{Tl}$ \\
\hline 39 & Turning Lathe & $\mathrm{T} 1$ \\
\hline 40 & Drill & D2, D3, 82 \\
\hline 41 & Vertical Milling Machine & M2 \\
\hline
\end{tabular}




\begin{tabular}{lll}
42 & Turning Lathe & T2 \\
43 & Slotting Machine & S2 \\
44 & Turning Lathe & T1 \\
45 & Slotting Machine & S2 \\
\hline
\end{tabular}

Tl - turning I; T2 turning 2; T3 -turning 3; B2 -boring; D2- drilling; D3 -drilling/ reaming; M2- milling; S3 shaping; G1 - grinding; S2 - slotting (vertical shaping).

Table 1. Machine tool set.

$\begin{array}{cl}\text { Components } & \text { Resource Element } \\ 1 & \text { S3 } \\ 2 & \text { Tl, D2, M2 } \\ 3 & \text { Tl, T2 } \\ 4 & \text { Tl, D3 } \\ 5 & \text { Tl } \\ 6 & \text { Tl } \\ 7 & \text { Tl,M2 } \\ 8 & \text { Tl, M2, D3, G1 } \\ 9 & \text { Tl,D2 } \\ 10 & \text { T1, S3 } \\ \text { II } & \text { Tl, B2, S2, T2 } \\ 12 & \text { Tl,D3 } \\ 13 & \text { Tl } \\ 14 & \text { Tl } \\ 15 & \text { S2, D2 } \\ 16 & \text { D3, T1 } \\ 17 & \text { D3 } \\ 18 & \text { D3 } \\ 19 & \text { D3, T1 } \\ 20 & \text { S2, D2, Gl } \\ 21 & \text { Gl } \\ 22 & \text { Gl, S3 } \\ 23 & \text { M2, D2 } \\ 24 & \text { D2, Gl } \\ 25 & \text { S3 } \\ 26 & \text { Tl, T2, S2 } \\ 27 & \text { T2, Tl, S2 } \\ 28 & \text { Tl, M2, S2 } \\ 29 & \text { M2 } \\ 30 & \text { M2, D2 } \\ 31 & \text { Tl,Gl } \\ 32 & \text { Tl, S2 } \\ 33 & \text { Tl, S2 } \\ 34 & \text { D2 } \\ 35 & \text { Tl, M2, D2 } \\ 36 & \text { D3,D1 } \\ 37 & \text { Tl, Gl } \\ 38 & \text { D2 } \\ 39 & \text { M2, D2 } \\ 40 & \text { Tl,M2 } \\ 41 & \text { Tl, D2 } \\ 42 & \text { T1 } \\ 43 & \text { Tl, S2, G1 } \\ 44 & \text { D2, D3 } \\ 45 & \text { M2, Tl } \\ 46 & \\ 47 & \text { Ml, D2 } \\ 48 & \\ & \end{array}$

$\begin{array}{cl}\text { Components } & \text { Resource Elements } \\ 61 & \text { T1 } \\ 62 & \text { S3 } \\ 63 & \text { Gl } \\ 64 & \text { D3 } \\ 65 & \text { D3 } \\ 66 & \text { S3, D3 } \\ 67 & \text { TI.M2 } \\ 68 & \text { Tl, D2 } \\ 69 & \text { Tl } \\ 70 & \text { D3.D1 } \\ 71 & \text { Tl. D3 } \\ 72 & \text { Tl, D2, Gl } \\ 73 & \text { T2 } \\ 74 & \text { S2 } \\ 75 & \text { D3,Tl } \\ 76 & \text { D3 } \\ 77 & \text { M2 } \\ 78 & \text { M2. S2 } \\ 79 & \text { Tl, S2 } \\ 80 & \text { S2. 82 } \\ 81 & \text { Tl, S3, D3 } \\ 82 & \text { D3, M2 } \\ 83 & \text { Tl, S2 } \\ 84 & \text { Tl. S3, D3 } \\ 85 & \text { Tl. D3 } \\ 86 & \text { S3, D3, Gl } \\ 87 & \text { Tl, S2 } \\ 88 & \text { D3,D2 } \\ 89 & \text { Tl, D3 } \\ 90 & \text { T2. D3. B2 } \\ 91 & \text { T2, D3 } \\ 92 & \text { Tl, T2, D3 } \\ 93 & \text { Tl } \\ 94 & \text { Tl } \\ 95 & \text { D2,GI } \\ 96 & \text { D3, S3, Gl } \\ 97 & \text { Gl } \\ 98 & \text { Tl } \\ 99 & \text { T1, D3 } \\ 100 & \text { Tl, B2, D3 } \\ 101 & \text { T2, B2.D3 } \\ 102 & \text { T2. 82 } \\ 103 & \text { T2, D3, Tl } \\ 104 & \text { T2, S2, D3 } \\ 105 & \text { T2, 82, S2, D3 } \\ 106 & \text { M2, D2 } \\ 107 & \text { M2, D2, D3 } \\ 108 & \\ & \end{array}$




$\begin{array}{llll}49 & \text { Tl } & 109 & \text { Tl, T2 } \\ 50 & \text { D2, Tl } & 110 & \text { Tl, D3 } \\ 51 & \text { S3, M2 } & \text { Ill } & \text { Tl,M2 } \\ 52 & \text { M2, Tl, D2 } & 112 & \text { T2 } \\ 53 & \text { Tl, S3 } & 113 & \text { Tl, M2, D2 } \\ 54 & \text { D3 } & 114 & \text { T1, D2 } \\ 55 & \text { D3 } & 115 & \text { D2 } \\ 56 & \text { G1, S3 } & 116 & \text { T1 } \\ 57 & \text { T2, D2 } & 117 & \text { T1 } \\ 58 & \text { D2,D3 } & 118 & \text { Tl } \\ 59 & \text { M2 } & 119 & \text { Tl, D3 } \\ 60 & \text { T2 } & \text { Tl }\end{array}$

Table 2. Component Data Set.

The final decision for selection of the actual machine tools allocated to a manufacturing cell is influenced by many factors (cost, batch size, availability, variety, processing cycle times, flexibility etc.). To illustrate the approach, the current work adopts a simplified decision making strategy aimed at minimising the variety of machines allocated to each machining cell. Accordingly, during cell formation preference is given to machine tools which contain the highest number of resource elements required by the components in each group. The machinebased validity measure $\mathrm{R}^{\mathrm{m}}$ is calculated at each iterative grouping step and is used to measure the quality of the clustering that is achieved.

A detailed summary of the full grouping procedure is given in the appendix A. A simplified numerical example is also included to illustrate the steps involved in the grouping procedure. For further details and background explanation of the algorithm refer to Gindy et al. (1995).

\section{Results}

In this paper, the ceil determination methodology is illustrated using a sample set of 120 components of similar work envelope and a variety of machining requirements selected from the manufacturing database of a large industrial company. The sample components are currently machined in a machine shop containing 45 machine tools. Based on an analysis of process planning information, each component was initially represented by both the set of form generating schemas and machine tools required for its manufacture.

The capability of the machine shop was described using 9 resource elements following the algorithm outlined in $\S 2.3$. The machine tools and their associated resource elements are shown in Table 1. In advance of applying the grouping procedure (see appendix A), each component was represented by the sequence of REs required for its processing as shown in Table 2.

The results of the cell determination methodology are summarised in Table 3. The 'best' partitioning occurred when the component set is divided into 4 groups coinciding with minimum compactness and repetition measure $\mathrm{R}^{\mathrm{m}}=0 \cdot 52$. $\mathrm{R}^{\mathrm{m}}$ decreases monotonically when the component set is divided into more than 5 groups. This is, therefore, considered as the value beyond which further grouping is considered infeasible (Xie and Beni 1991). The functional capability requirements of the defined cells, represented in terms of REs, and the actual machine tools allocated for component processing are shown in Fig. 6.

To provide a comparative evaluation of the resource element-based approach to grouping

\begin{tabular}{lll}
\hline Partition & Validation measure $\mathrm{R}^{\mathrm{m}}$ & Group deviation \\
\hline
\end{tabular}


International Journal of Production Research Vol. 34, No. 3, pp727-752, 1996

\begin{tabular}{cccc}
\hline (Number of cells) & $\begin{array}{c}\text { (Compactness and } \\
\text { Repetition) }\end{array}$ & $\begin{array}{c}\text { (Compactness } \\
\text { measure } \lambda \text { ) }\end{array}$ & $\begin{array}{c}\text { Repetition } \\
\text { Measure } r\end{array}$ \\
2 & 0.67 & 0.67 & 1 \\
3 & 0.72 & 0.62 & 1 \\
4 & 0.52 & 0.52 & 0.85 \\
5 & 0.63 & 0.54 & 0.93 \\
6 & 0.51 & 0.48 & 0.94 \\
7 & 0.46 & 0.43 & \\
\hline
\end{tabular}

Table 3. Cell formation results for 120 components using resource element concept.

Cell 1

Component group requirements: Resource elements
$\mathrm{M} 2\left(0.42^{*}\right), \mathrm{D} 3(0.19), \mathrm{T} 1(0.30)$,
$\mathrm{G} 1(0.57), \mathrm{S} 2(0.53), \mathrm{D} 2(0.48)$

Cell 2

Component group requirements: Resource elements
$\mathrm{T} 1(0.29), \mathrm{B} 2(1), \mathrm{S} 2(0.47), \mathrm{T} 2(0.80), \mathrm{D} 3(0.45)$

Cell 3
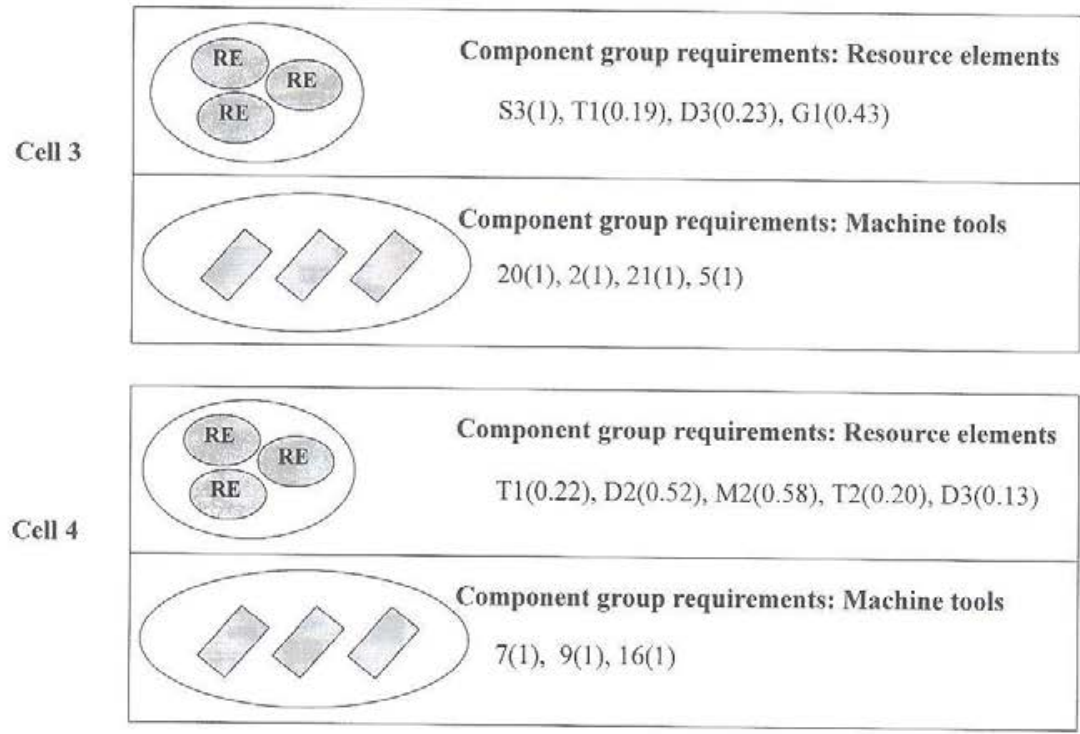

* Resource element membership shown in brackets ** Machine tool membership shown in brackets 


\begin{tabular}{cccc}
\hline $\begin{array}{c}\text { Partition } \\
\text { (Number of cells) }\end{array}$ & $\begin{array}{c}\text { Validation measure } \mathrm{R}^{\mathrm{m}} \\
\text { (Compactness and }^{\text {Repetition) }}\end{array}$ & $\begin{array}{c}\text { Group deviation } \\
\text { (Compactness } \\
\text { measure } \lambda \text { ) }\end{array}$ & $\begin{array}{c}\text { Repetition } \\
\text { Measure r }\end{array}$ \\
2 & 0.97 & 0.92 & 0.94 \\
3 & 0.98 & 0.89 & 0.91 \\
4 & 0.89 & 0.84 & 0.94 \\
5 & 0.92 & 0.82 & 0.88 \\
6 & 0.94 & 0.78 & 0.83 \\
7 & 0.86 & 0.73 & 0.85 \\
\hline
\end{tabular}

Table 4. Cell formation results for 120 components using component-machine formalisation.

tasks proposed in this work, and the conventional approach based upon machine incidence, the sample components were also grouped based on the machine tools actually used for their processing. The machine-based grouping results are shown in Table 4 and Fig. 7. The component-machine incidence information was based on processing routes selected by process planners and actually used for component processing and the same grouping algorithm used as in the case of RE- based grouping.

Experiments based on samples of 200, 400 and 600 components were carried out in order to investigate the differences between the cell formation using RE-based and machine tool-based grouping. The results of the experiment are shown in Figs 8, 9 and 10.

\section{Discussion}

Traditionally, component processing requirements are described by the sequences of machine tools required for their manufacture. The significant increase in the capabilities of modern machine tools has made this level of abstraction not discriminating enough for use in many manufacturing applications. The machine-based formalisation of manufacturing information does not take into account the scope of the capability of modern machine tools and which part of it should be the real target for processing individual components. Machine tools which appear in the component routeing information, in many cases possess extra capability over and above what is strictly needed for component processing. An example of such a case is when machining centres are selected for manufacturing simple components which do not require the utilisation of their full capabilities. At the 'whole' machine level of abstraction it is 
impossible to identify, measure and therefore utilise the extra unused machine capability. As a result, opportunities for optimising the utilisation of resources when processing several components may be lost.

The specific characteristics of the manufacturing system are also one of the important aspects which are not fully taken into account if the capabilities of machining facilities is represented as a 'whole' machine tool. Every machining facility is unique in terms of the exclusive and shared resources contained within its boundary. The flexibility of a manufacturing system is dependent, more than anything else, upon number of repeated resources and the similarity and uniqueness of its resources. This information is much more meaningful and is better decided at the sub- machine tool level.

One of the difficulties experienced when judging component similarity during grouping for cell formation is that component process planning information is normally route-dependent.
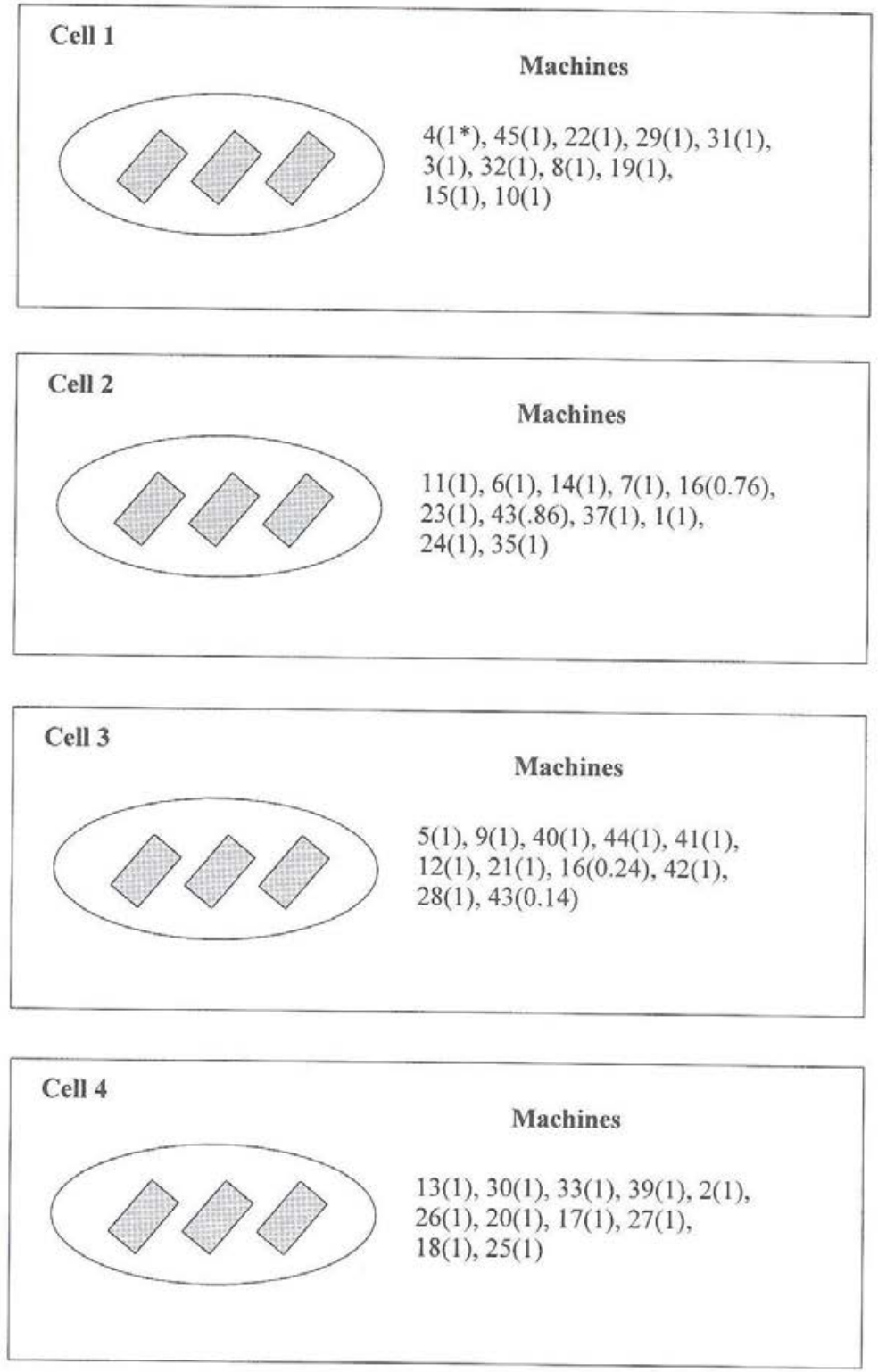

* Machine membership shown in brackets 
Figure 7. Machine based cell formation.
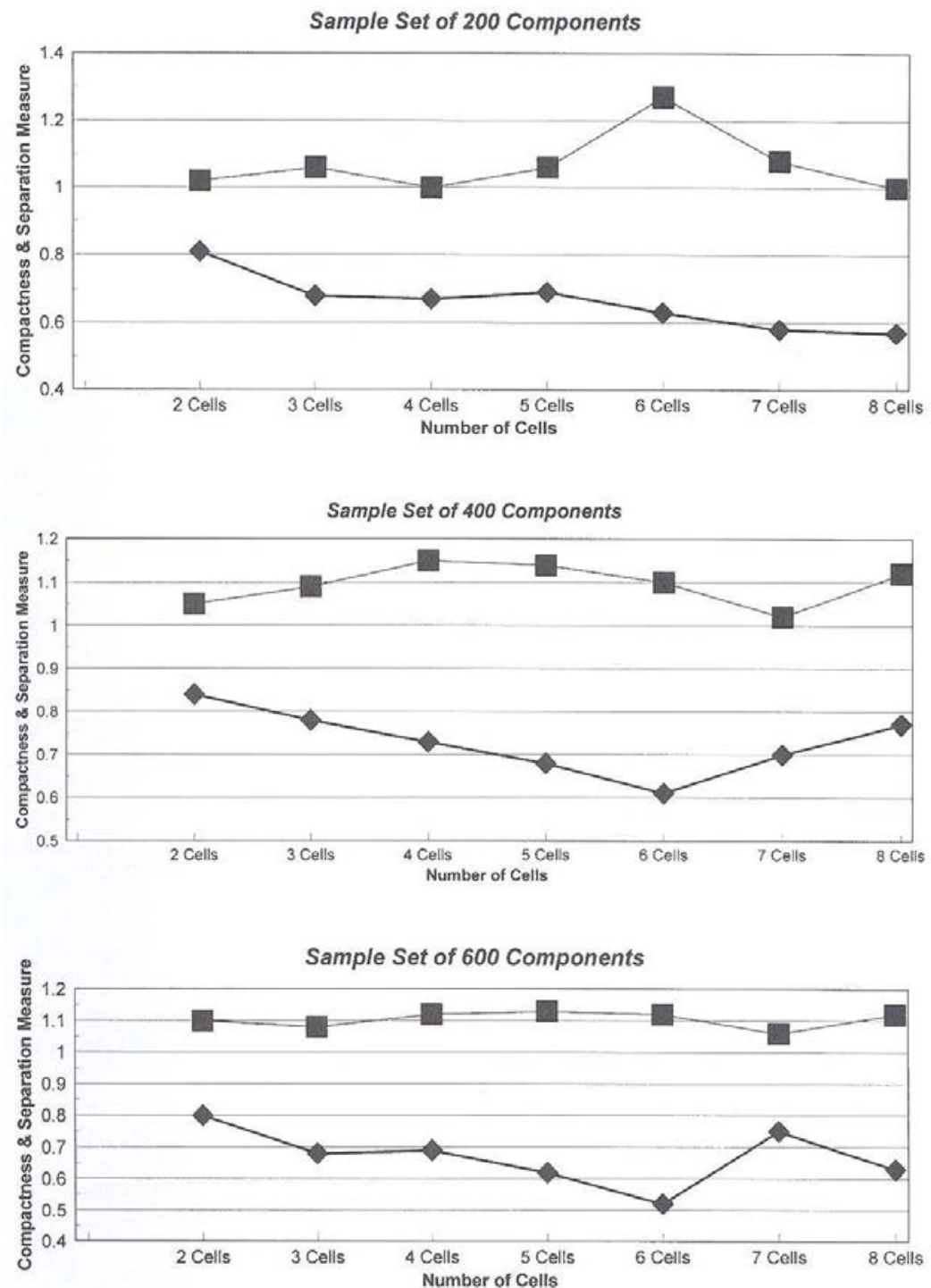

Machine based grouping RE based grouping 
Figure 8. Resource element and machine tool based cell formation - statistical results using different component samples.
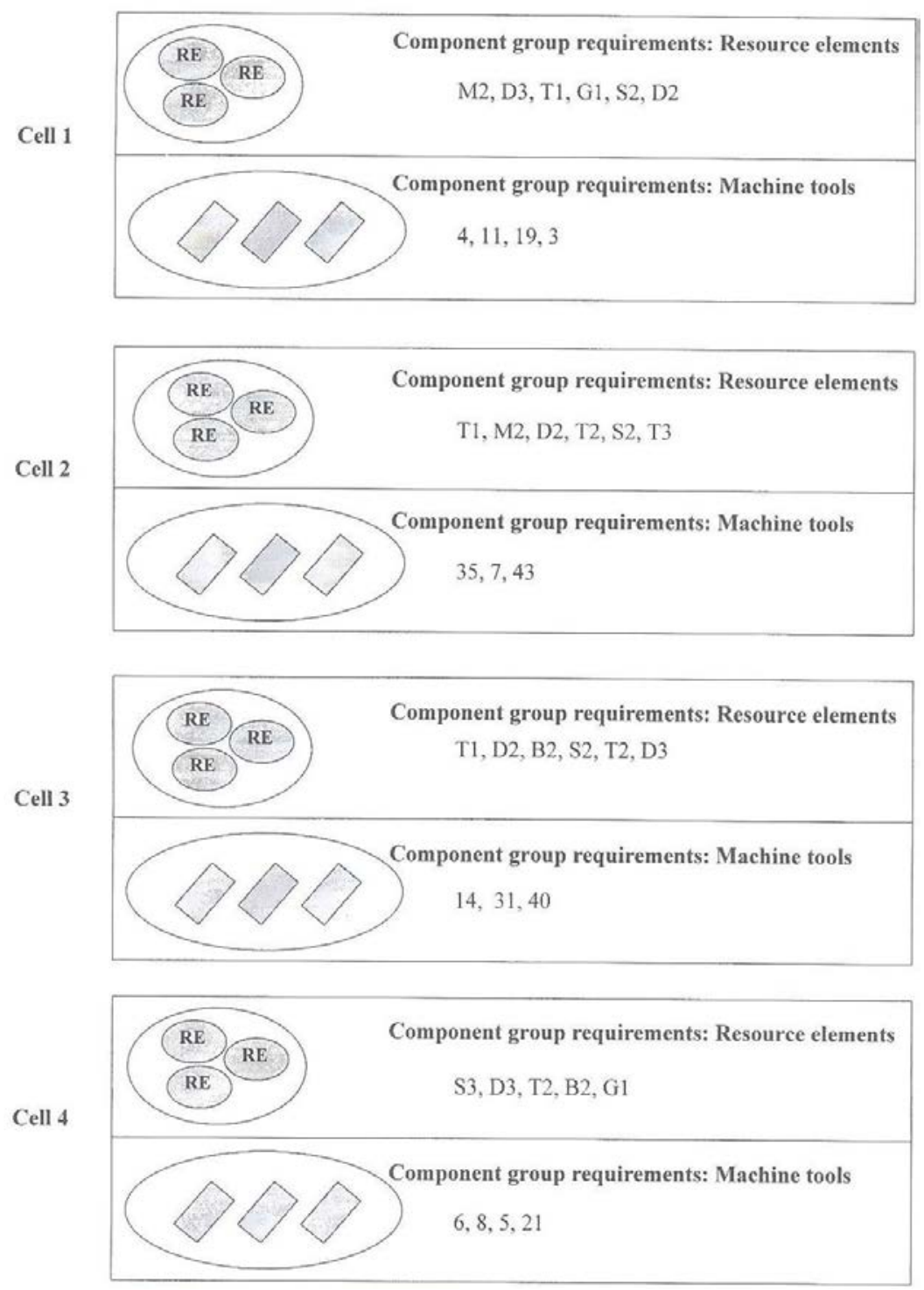
Figure 9. Cell formation results for 200 component sample.

Machine-based similarity definition is influenced directly by the specific machines selected by the individual process planners and alternative routes are not normally considered. The resulting definition of component similarity is therefore fuzzy and possibly inaccurate.

Component group requirements: Resource elements
$\mathrm{M} 2 \mathrm{D} 3 \mathrm{~T} 1 \mathrm{G} 1 \mathrm{~T} 2 \mathrm{~S} 2 \mathrm{D} 2$


Resource elements can be considered as generic capability units which allow sub-machine representation of component processing needs and therefore a greater level of detail in representing manufacturing information. This finer assessment of component processing needs should enable better capture of the generic similarity between components which also take into account the specific characteristics of the machining facility in which components are manufactured. The RE-based similarity definition is route-independent and is directly related to the capabilities of the available machine tools in a machine shop. RE-based component group formation therefore should lead to more compact component groups and less repetition of the manufacturing resources needed for component group manufacture.

Tables 3 and 4 show the RE-based and machine-based grouping results respectively. From the tables it can be observed that the 'best' group partitioning has not changed; the minimum value of $\left(\mathrm{R}^{\mathrm{m}}\right)$, in both cases, still occurs when the component set is divided into 4 groups. However, a closer look at the compactness and repetition measures show that the RE-based groups are more compact (group deviation $\lambda=0.52$ compared to 0.84 in machine based cell determination) with less repetition of the machine tools required for group processing (no repetition $r=1$ using REs compared with 2 repeated machines $r=0.94$ when using machines).

This can be attributed to the fact that the machine tools allocated to components during process planning are selected individually for each component without due consideration of the processing requirements of other components that may be clustered with it into a group. This leads to less commonality overall between the resources allocated to the component groups. The result is that components belonging to a group have less similar machine-based routes compared with the results produced using REs. The machine-based component groups have a higher component deviation from group centroids, i.e. they are less compact than their resource elements-based counterparts. Cells formed on this basis are, therefore, less compact, often containing machines which are not used to their full potential capability leading to lower utilisation of cell equipment.

In contrast, RE-based grouping allows machine tool selection to be carried out after clustering the components into groups based on their generic processing needs. A clear advantage of adopting this approach is that machines are selected with knowledge of the 
collection of resources elements required by component cells, at every iterative step of the cell definition procedure. Machine selection therefore reflects not only individual component requirements, but also takes into account the collective requirements of all the components clustered into a group. As a result, the defined machining cells are more compact, reflect better the processing needs of the group members and should lead to fewer machines and higher utilisation of the equipment selected for the cell. Figure 8 shows the results obtained from RE based and machine based grouping for component sample sizes of 200, 400 and 600 components. In all cases investigated the cells formed using resource elements have lower values of the validity measure $\mathrm{R}^{\mathrm{m}}$ compared with the cells formed based upon machine incidence.

As expected, increasing the component sample size increases the number of resulting component groups and leads to changes in the cell content (the machine tools allocated to each cell). The increase is not proportional, the number of cells defined for 120 and 200 components remains 4 cells while the number of cells defined for 400 and 600 component samples increases to 6 .

Comparing the cell content defined for the various component sample sizes (see Figs 6, 9, 10) it can be observed that there are broad similarities between the defined cells. Cells no. 1 for 120 and 200 components are identical and increasing the sample size to 400 components changes the cell content only by one machine tool.

Research is ongoing to widen the scope of the investigation to include statistical experiments to investigate the influence of the component variety, sample size, and the number of available machine tools in the manufacturing facility during RE-based cell formation. What can be stated, based upon the results to date, however, is that the number of cells defined using resource elements is either equal to or lower than the number of cells defined using machine tool based component routeings. The lower number of cells is due to the fact that components are initially partitioned based on capability requirements thus providing more accurate assessment of the cell boundaries. In contrast, when machine tool based component routes are used for cell determination, the cell boundaries inherit the inaccuracy of the machine selection process performed at the process planning stage and hence they may include unused machine capabilities.

The advantages of using generic representation of component processing requirements in cell formation are further underlined by comparing the 'optimum' number of cells (see Fig. 8). Resource elements provide better correlation between the component processing requirements, number of cells and number of selected machine tools. The overall number of machine tools required by each component sample increases with the number of cells rather than the number of components in the sample. For 120 and 200 components the number of machine tools is the same (14) while the number of machine tools for the set of 400 components is higher (21). In contrast when the grouping procedure uses machine based component routeings the number of machine tools is pre-defined and is not related to the number of cells or to the level of similarity between components.

The RE level of representation of machine tool capabilities and component processing requirements can also be utilised to achieve better integration between manufacturing applications. For example if process planning is performed at the full machine tool level, then a cell scheduling system can only relate to this level of detail. On the other hand if process 
planning is done at the resource element level, then the cell scheduling can be performed in the knowledge of the common and repeated RE distributed in the manufacturing system. Taking into account the extra alternative routes that may be available for part manufacture would allow better cell performance.

\section{Conclusions}

In this work, a new methodology for representing manufacturing information at submachine capability level which utilises generic capability units termed 'resource elements' is presented. The concept of resource elements allows the processing requirements of components and the capabilities of machine tools and machining facilities to be described at a greater level of detail than the conventional machine-based approach. Being machine independent and facility specific, the resource element provides a useful level of abstraction for different manufacturing applications. It allows better discrimination in determining the processing needs of components and higher accuracy in matching them to the capabilities of machine tools, taking into account the characteristics of the machining facility to be used for their manufacture.

A cell formation approach utilising resource elements as basic grouping primitives is proposed. The approach allows component groups to be formed based on generic component similarity in terms of processing requirements described by resource elements. Representing the component group requirements and the capabilities of the machine tools by resource elements provides a basis for selecting the most 'appropriate' machine tools for each component group. The results of the comparative evaluation of the RE-based grouping and the machine-based grouping shows that the use of RE as the primary grouping attribute leads to component groups that are more compact with better matching between the processing requirements of components and the capabilities of the machine tools selected for their processing.

Work is ongoing to widen the scope of the research and investigate the applicability of the resource element concept in other manufacturing applications particularly as an integrating framework for process planning and scheduling systems.

\section{Acknowledgement}

The reported research is supported by a research grant provided by CDP committee of the EPSRC in the UK. Their financial contribution is gratefully acknowledged.

\section{Appendix A: Concurrent grouping algorithm}

Step 1. Form initial component groups. The processing needs of components are represented by set of resource elements required for their manufacture. The definition of grouping centroids is based upon finding the most distant components requiring the largest number of resource elements. The centroids $G_{1}^{0}$ and $G_{2}^{0}$ the first division of components into two groups are defined as:

$$
\begin{gathered}
G_{1}^{o} \equiv C_{k} \text { and } G_{2}^{0} \equiv C_{p} \\
\text { if } \exists\left(C_{k}, C_{p}\right) \in Q \text { for which } d\left(C_{i}, C_{p}\right)=\max _{i j} d\left(C_{i}, C_{j}\right)
\end{gathered}
$$

where $d\left(C_{k}, C_{j}\right)$ is a component distance measure. 
Each successive group centroid is defined by finding the most distant component to the already selected clustering centroid:

$$
\begin{gathered}
G_{k+1}^{0} \equiv C_{p}, \\
\text { if } \exists C_{p} \text { for which } d\left(C_{p}, G_{k}\right)=\max _{i j}\left(\min _{i j} d\left(C_{i}\right), G_{j}\right)
\end{gathered}
$$

Thus, each cluster prototype is guaranteed to be the data point which is less likely to be clustered to any of the existing grouping prototypes and therefore is most likely to be a natural concentration point.

Step 2. Update the fuzzy membership function. The distribution of components around grouping centroids is based on the fuzzy function $\mu_{i j}$ representing the degree of membership of component $C_{i}$ to group centroid $G_{j}$ :

$$
\sum_{j=1}^{m} \mu_{i j}=1
$$

where $m$ is the total number of groups.

The component membership function is defined as:

$$
\mu_{i j}=\frac{\left(\frac{1}{e^{2\left(c_{j}, G_{i}\right)}}\right)^{\frac{1}{(f-1)}}}{\sum_{i=1}^{m}\left(\frac{1}{e^{2\left(c_{j}, G_{i}\right)}}\right)^{\frac{1}{(f-1)}}}
$$

where $e^{2}\left(C_{j}, G_{i}\right)$ is an Euclidean norm of component vectors $C_{j}$ and group centroids $G_{i}$ and $f>$ 1 is the fuzziness index (Bezdek 1980).

Step 3. Update the grouping centroids $G_{r}$. Vectors, describing fuzzy grouping centroids $G_{i}(i$ $=1,2 \ldots, m$ ), are defined based on the frequency of appearance of different resource elements in the components belonging to the group. Their coordinates $g_{i j}$ are defined as membership functions of the resource elements, indicating their affinity to different groups:

$$
g_{i k}=\frac{\gamma_{i k}}{\sum_{j=1}^{m} \gamma_{j k}}
$$

where $\gamma_{i k}$ is defined as the weighted sum of the component coordinates representing machine $k$ and belonging to group $i$ :

$$
\gamma_{i k}=\frac{\sum_{j=1}^{n_{i}}\left(\mu_{i j}\right)^{f} c_{j k}}{\sum_{j=1}^{n_{i}}\left(\mu_{i j}\right)^{f}}
$$

Step 4. Compute compactness and repetition validity measure $R^{r}$-based on REs. Optimum partition of components into groups is reached when maximum group compactness and 
minimum group overlapping is achieved. This is indicated by a minimum value of the RE-based validity measure $R^{r}$, defined as ratio of the average compactness of components in the groups $\lambda$ (calculated using REs) to the repetition of the resource elements $r$ attached to that group.

The average compactness of the partition is defined as:

$$
\lambda=\frac{1}{m} \sum_{j=1}^{m} \lambda_{i}
$$

where $\lambda_{j}$ measures the component deviation of each group:

$$
\lambda_{j}=\frac{1}{q_{j}} \frac{1}{n_{j}} \sum_{j=1}^{n_{j}} \mu_{i j} e^{2}\left(C_{i}, G_{j}\right)
$$

and $q_{j}$ is the number of resource elements belonging to group $\mathrm{G}_{\mathrm{i}}$ (number of the coordinates in the centroid vector $g_{i j}>0$ ) and $n_{j}$ is the number of components belonging to the group.

The overlapping of the grouping centroids, measured by the RE-based repetition measure $r$,

is defined as:

$$
r=\frac{1}{m} \sum_{i=1}^{m} \frac{1}{q_{i}}\left(G_{i}\right)^{2}=\frac{1}{m} \sum_{i=1}^{m} \frac{1}{q_{i}} \sum_{j=1}^{q_{i}}\left(g_{i j}\right)^{2}
$$

where $g_{i j}$ is membership function of resource element $R_{j}$ to group $G_{i}$.

Step 5. Define the optimum partition for the current number of groups. Steps 2, 3, 4 and 5 are repeated updating iteratively group centroids and membership functions until the value of RE-based validity function $R^{r}$ for the current number of groups is no longer decreasing.

Step 6. Select machine tools for each cell. Machine tools are selected using a set of preferences in accommodating the resource elements representing the capabilities of each cell. Following the selected strategy, each machine is evaluated in terms of the number of REs common to different group centroids. Machines are then clustered around the group centroids, substituting correspondent REs. The process is based on substituting the maximum number of REs at each step by including the most capable machines. The procedure is completed once all REs representing the processing requirements of the component partition are substituted by machines.

Step 7. Calculate machine tool based validity measure $R^{m}$. Each partition is assessed using machine tool based validity measure $R^{m}$ :

$$
R^{m}=\frac{\lambda}{r}
$$

where compactness $\lambda$ and repetition $r$ are the same as in equations (16) and (18) but are 
calculated based on the machines selected for each cell.

Step 8. Increase the number of groups $m=m+1$

Step 9. Repeat steps 1-8 until $m=m^{0}$ (stop-value).

A number of heuristic methods can be used to determine the stop-value beyond which the grouping is not feasible. One of the possible methods is to define the optimum value for $R^{m}$ for $m=2,3, \ldots, n-1$, and select the starting point of monotonically decreasing tendency as the maximum group number to be considered (Xie and Beni 1991).

Step 10. Select the partition with minimum $\mathrm{R}^{\mathrm{m}}$. A cluster partition $\Omega_{\mathrm{m}}$ with minimum validity measure $R^{m}$ is selected as an optimum set of component groups/machining cells:

$$
\min _{2 \leq m \leq m^{0}}\left(\min _{\Omega_{m}} R^{m}\right)
$$

\section{Appendix B: Cell formation algorithm-an illustrative example}

\begin{tabular}{cllll}
\hline \multirow{2}{*}{ Component Processing Requirements } & & \multicolumn{2}{c}{ Machine Tool Capabilities } \\
\cline { 4 - 4 } Components & Resource Elements & & Machine Tools & Resource Elements \\
1 & RE1 & & 1 & RE1, RE2 \\
2 & RE1. RE2 & 2 & RE1 \\
3 & RE1 & 3 & RE2 \\
4 & RE1 & 4 & RE1, RE2, RE3 \\
5 & RE1, RE2, RE5 & 5 & RE2. RE3 \\
6 & REL RE4 & 6 & RE1, RE3 \\
7 & RE1. RE2, RE5 & 7 & RE2, RE4 \\
8 & RE2 & 8 & RE2, RE5 \\
9 & RE2, RE5 & & \\
10 & RE1 & & \\
\hline
\end{tabular}

Step 2.

Step 1.

$\begin{array}{cccccc}\text { Group } & \text { RE1 } & \text { RE2 } & \text { RE3 } & \text { RE4 } & \text { RE5 } \\ 1 \text { (Component 6) } & 1 & 0 & 0 & 1 & 0 \\ 2 \text { (Component 9) } & 0 & 1 & 0 & 0 & 1\end{array}$

$\begin{array}{ccccccccccc}\text { Components/ Group } & 1 & 2 & 3 & 4 & 5 & 6 & 7 & 8 & 9 & 10 \\ 1 & 0.75 & 0.5 & 0.5 & 0.75 & 0.25 & 1 & 0.25 & 0.25 & 0 & 0.75 \\ 2 & 0.25 & 0.5 & 0.5 & 0.25 & 0.75 & 0 & 0.75 & 0.75 & 1 & 0.25\end{array}$

Step 3.

$\begin{array}{cccccc}\text { Group } & \text { RE1 } & \text { RE2 } & \text { RE3 } & \text { RE4 } & \text { RE5 } \\ 1 & 0.57 & 0 & 0 & 1 & 0\end{array}$

Step 6. Cell 1 (Machine tools: 4, 7)

Step 7. $R^{m}=0.27$

Step 8. Number of Groups: $m=m+1$

Step 9. Repeat steps 1-8

$R^{m}=0.31$ (3 groups)

$R^{m}=0.19$ (4 groups)

Step 10. Select best partition:

Partition with 2 Groups/Cells 


\section{References}

BEZDEK, J., 1980, A convergence theorem for the fuzzy ISODATA clustering algorithms. IEEE Transactions on Pattern Analysis and Machine Intelligence, 2(1), 1-8.

CHANG, T. C., 1990, Expert process planning for manufacturing (Reading, MA: Addison-Wesley).

GINDY. N. N. Z., 1989, A hierarchical structure for form features. International Journal of Production Research, 27(12), 2089-2103.

GINDY, N. N. Z., HUANG, X., RATCHEV, T. M., 1993, Feature based component model for computer aided process planning systems. International Journal of Computer Integrated Manufacturing, 6(1 and 2), 20-26.

GINDY, N. N. Z., RATCHEV, T. M., CASE, K., 1995, Component grouping for GT applications-a fuzzy clustering with validity measure. International Journal of Production Research, 33(9), 2493-2509.

GUPTA, T., 1993, Design of manufacturing cells for flexible environment considering alternative routeing. International Journal of Production Research, 31(6), 1259-1273.

KANG, S. L. and WEMMERLOV, U., 1993, Load oriented heuristic methodology. European Journal of Operational Research, 69, 292-311.

KAUFFMANN, A., 1975, Introduction to the Theory of Fuzzy Subsets (New York: Academic Press).

KUSIAK, A., 1990, Intelligent Manufacturing Systems (Englewood Cliffs, NJ: Prentice Hall).

KING, J. R. and NAKORNCHAI, V., 1982. Machine component group formation in group technologyreview and extension. International Journal of Production Research. 20(2), 117-133.

SINGH, N., 1993, Design of cellular manufacturing systems-an invited review. European Journal of Operation Research, 69(3), 284-291.

SRINIVASAN. G. and NARENDRAN, T. T., 1991, GRAFICS-a nonhierarchical clustering algorithm for group technology. International Journal of Production Research, 29(3), 463-478.

VARIAX, 1994, Giddings \& Lewis @ Inc., Fond Du Lac, Wis., USA.

WEMMERLOV, U. and HYER, N. L., 1989, Cellular manufacturing in US industry: a survey of users. International Journal of Production Research, 27(9), 1511-1530.

WARREN, G. and MOODIE, C., 1993, Cellular Manufacturing, Report TAP930104. Purdue University, West Lafayette, Ind., USA.

XIE, X. L., BENI, G., 1991, A validity measure for fuzzy clustering, IEEE Transactions on Pattern Analysis and Machine Intelligence, 13(8), 841-847. 
International Journal of Production Research Vol. 34, No. 3, pp727-752, 1996 